Review

\title{
Fracture Failure Modes in Fiber-Reinforced Polymer Systems Used for Strengthening Existing Structures
}

\author{
Valentino Paolo Berardi
}

Citation: Berardi, V.P. Fracture Failure Modes in Fiber-Reinforced Polymer Systems Used for Strengthening Existing Structures Appl. Sci. 2021, 11, 6344. https:// doi.org/10.3390/app11146344

Academic Editor: Filippo Berto

Received: 10 May 2021

Accepted: 7 July 2021

Published: 8 July 2021

Publisher's Note: MDPI stays neutral with regard to jurisdictional claims in published maps and institutional affiliations.

Copyright: (C) 2021 by the author. Licensee MDPI, Basel, Switzerland. This article is an open access article distributed under the terms and conditions of the Creative Commons Attribution (CC BY) license (https:/ / creativecommons.org/licenses/by/ $4.0 /)$.
Department of Industrial Engineering, University of Salerno, 84084 Fisciano, SA, Italy; berardi@unisa.it

\begin{abstract}
The development of promising new high-performance materials, such as composite materials made of fibers in a polymeric resin (fiber-reinforced polymer, or FRP), has transformed the structural rehabilitation and upgrade industry for buildings and infrastructure. Conventional materials and construction techniques (e.g., strengthening with externally bonded steel plates, known as beton plaqués, or steel/concrete jackets) have been supplanted by innovative ones. The most important emerging techniques involve the use of externally bonded composites as a quick and effective option for repairing and upgrading existing structures. Several issues regarding FRP-substrate interaction, mainly related to brittle failure mechanisms due to fracture phenomena, remain the focus of a great deal of research. This paper presents an overview of debonding behavior and its predictive modelling in externally bonded FRP systems.
\end{abstract}

Keywords: retrofitting; FRP; debonding phenomena

\section{Introduction}

The preservation over time of existing structures and infrastructure, in particular historical buildings, against static and seismic vulnerability, is an important priority. Ageing, degradation under specific environmental conditions (e.g., alkaline environments, moisture, extreme temperatures, thermal cycles, freeze and thaw cycles, or ultraviolet radiation), poor initial design and/or construction, a lack of maintenance, and uncontrollable events such as earthquakes can all affect the structural integrity of existing buildings. Moreover, structural decay may be combined with the need for upgrades in order to satisfy new design requirements (e.g., live load increments exceeding the initial design loads, seismic upgrading).

Several innovative retrofit and upgrade techniques can be applied for strengthening the design of structures subject to axial, flexural, and shear loads. Some of these, based on externally bonded FRP systems [1-4], or fabric-reinforced cementitious matrix (FRCM) composites [5-8], as well as on near-surface-mounted FRP reinforcement, have been remarkably successful in the last two decades [9-11].

The use of FRP materials represents a quick and an effective reinforcement intervention, as well as guaranteeing the reversibility of the intervention-an attractive aspect, especially with regard to historical buildings.

No international standards exist on the design and verification of the strengthening of civil reinforced concrete and masonry structures with FRPs, but some technical recommendations are suggested in the American Concrete Institute's ACI 440.2R-17 guide [12], the European Fib technical reports [13,14], and the Italian CNR-DT 200 R1/2013 [15] guidelines. Although there are numerous advantages to this strengthening technique, it suffers from a degree of uncertainty in predicting reinforcement-substrate interface behavior and its failure mechanisms. More specifically, these mechanisms depend on the specific type of junction, i.e., whether it involves an adhesive interface or an anchorage device. Adhesive junctions are the most common type of reinforcement intervention, and their failure is generally caused by a local failure. 
Several experimental investigations have been performed on strengthened concrete elements $[1,2,16-19]$ and, more recently, on reinforced masonry members $[3,4,20,21]$. These investigations have shown that the rupture of retrofitted existing elements is, indeed, not characterized by global failures (such as a failure in shear or in flexure) but by local ones, due to debonding phenomena.

The mechanisms, or modes, of debonding have been investigated in various studies, from a theoretical point of view, in order to formulate reliable mechanical models, based either on identification of a direct Cohesive Zone Model (CZM) by means of shear interface stresses and slips [16-23], or on the primary analytical relationship between the J-integral (first introduced by Rice) and the cohesive traction [24-28].

Recent studies on the direct evaluation of the interface law via a shear interface stressslip diagram [20-23] have been based on the predictive approximated nonlinear strain law (proposed by Ali-Ahmad et al. [19]) in the stress transfer zone. The use of this method has led to the relevant dispersion of experimental longitudinal strains with respect to the predictive non-linear strain distribution [19-23].

On the contrary, approaches based on the J-integral [24-28] are less approximate, due to a limited dispersion of the experimental J-integral values with respect to the predictive J-integral distribution.

On the other hand, more accurate methods to predict debonding failure are still needed. The design procedures proposed in [12-15] suggest conservative approaches which place significant limitations on the strain achieved (and, thus, the stress achieved) in the FRP material, to take into account debonding failure modes. The above-mentioned recent developments provide more thorough methods for predicting debonding via a cohesive law.

\section{Fiber-Reinforced Materials}

Continuous fiber-reinforced polymers (FRPs) are composite, heterogeneous, and anisotropic materials, characterized by a prevalent linear elastic behavior up to failure.

They are widely used in several fields of engineering, including civil engineering, for strengthening existing structures. As well as being virtually maintenance free, these innovative materials exhibit many advantages, such as:

- Lightness;

- $\quad$ High strength-to-weight ratio;

- Corrosion-resistance;

- Versatility;

- Electromagnetic transparency.

Two main types of structural strengthening composite are available on the market: pultruded profiles and laminates made with uni-directional or bi-directional fabrics (Figure 1).

From a constitutive point of view, FRPs are made of two or more materials (phases) which have different natures and are macroscopically distinguishable. The composite's physical and mechanical properties are different than those of its individual constituents.

The fabrication of fiber-reinforced composites with polymeric matrices involves the combination of an organic polymeric matrix and inorganic (e.g., carbon, glass, aramidic, ceramic) reinforcing fibers.

The versatility of these materials allows the designer to control their stiffness and strength in specific directions. 

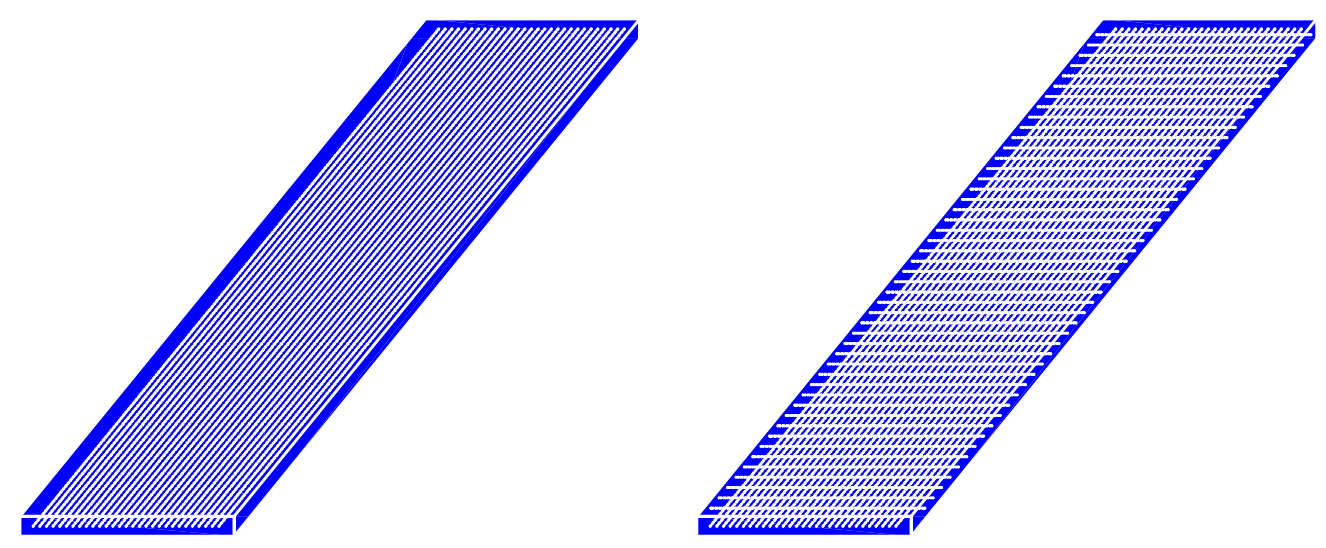

Figure 1. Composite with one-directional fabric (left), bi-directional fabric (right).

\section{Debonding Failure Modes}

The main causes of failure in FRP-strengthened concrete elements due to debonding are:

- $\quad$ Mode 1: Cutoff cross-section debonding;

- $\quad$ Mode 2: Debonding by flexural cracks;

- $\quad$ Mode 3: Debonding by diagonal shear cracks;

- Mode 4: Debonding by irregularities and roughness of surface.

The first mode occurs at the FRP end, due to high tangential stresses at the interface over an anchorage area, and is related to a typical Mode II fracture failure located close to a superficial volume of the substrate (e.g., concrete cover, superficial portion of a brick) (Figure 2).

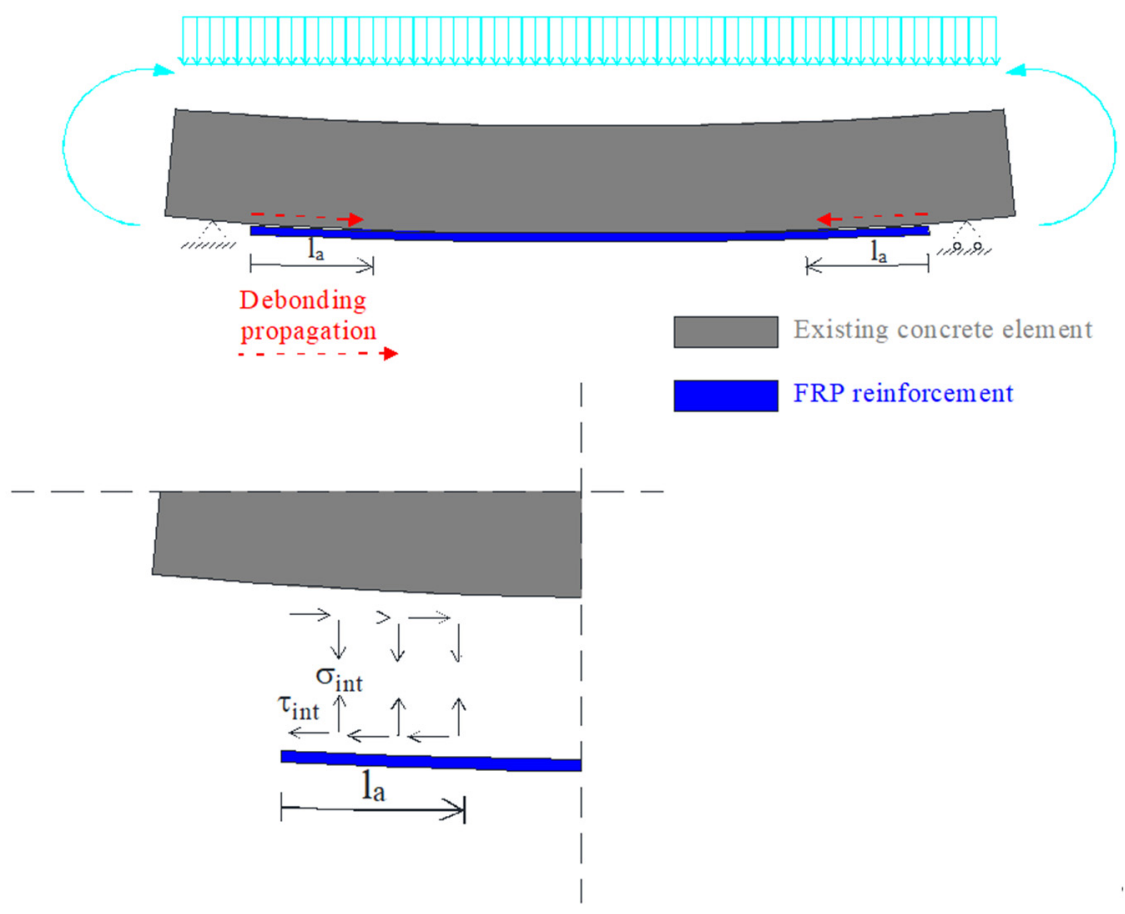

Figure 2. Cutoff cross-section debonding.

In the case of strengthening with laminates (e.g., pultruded laminae), the interface may be also subject to normal stresses perpendicular to the interface (peeling stresses), due to the non-negligible stiffness of the reinforcement. These normal stresses may modify the failure mode, leading to a mixed Mode I and Mode II fracture failure mechanism. 
Mode 2 debonding is also due to a Mode II fracture failure, but generally located close to cross-sections of an element subject to a bending moment greater than the cracking moment. In such zones, discontinuities in the substrate generate stress concentrations at the interface that may cause full or partial debonding (Figure 3).

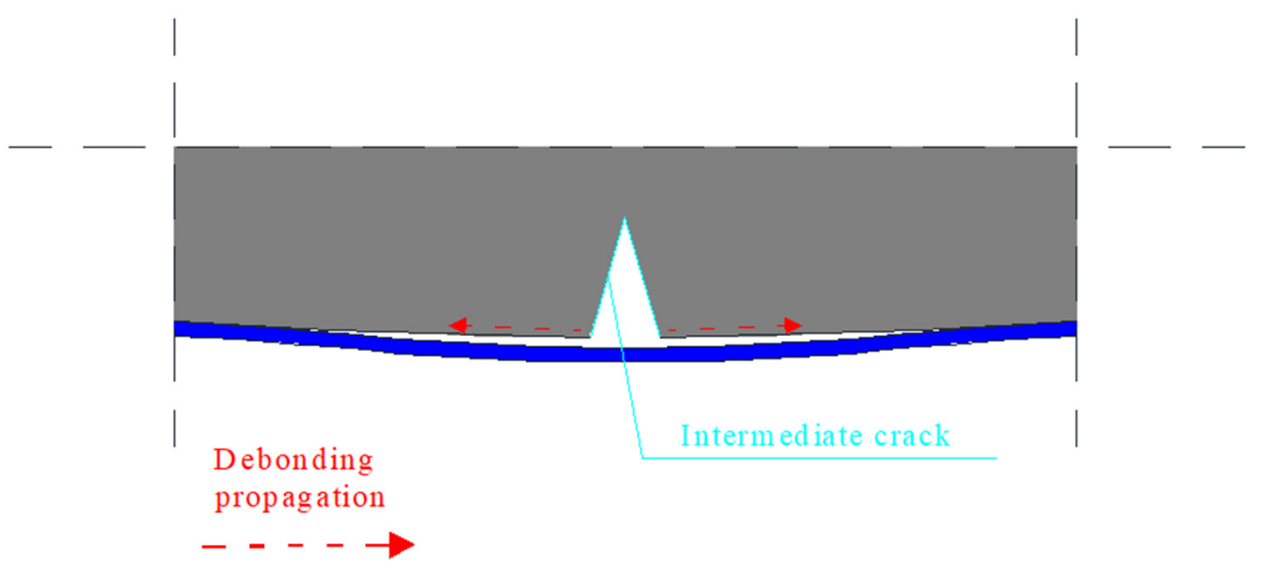

Figure 3. Debonding due to vertical cracks.

Mode 3 debonding is caused by diagonal shear cracks, and may occur when shear is predominant over bending moment (e.g., in the case of thick beams) (Figure 4). The corresponding failure mode is characterized by a mixed Mode I and Mode II fracture failure mechanism, because the normal slip caused by the relative displacement between the edges of the crack generates significant normal stresses.

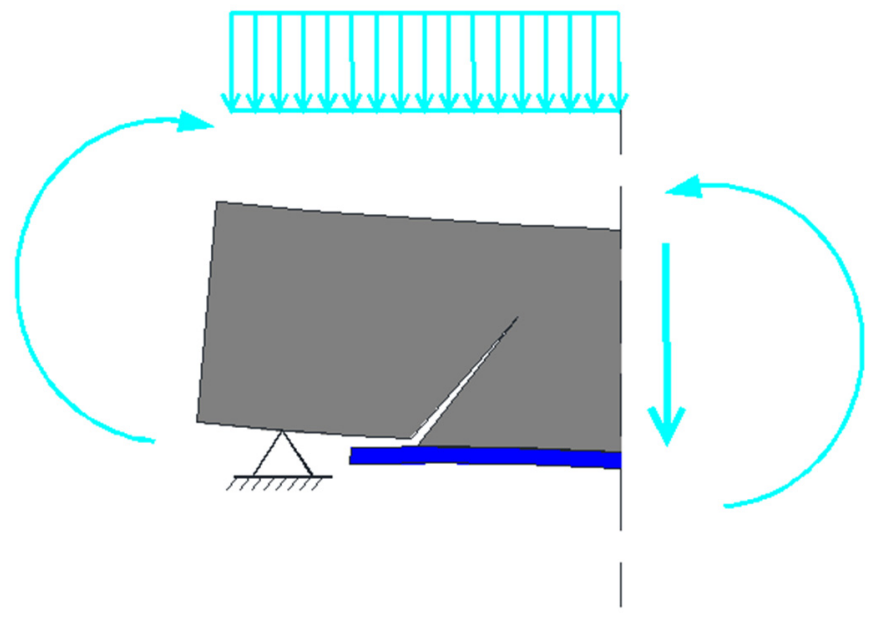

Figure 4. Debonding due to vertical cracks.

Such a collapse does not generally occur in beams subjected to a distributed load, but rather takes place most commonly in laboratory tests of the four-point bending type, and less frequently in situations of transverse distributed load.

Mode 4 occurs due to the unevenness and roughness of the concrete surface, and may initiate a full debonding of the material. This failure mode can be avoided by regularizing the surface of the strengthening application.

\section{Simplified Design Procedures}

All the international guidelines suggest a simple approach based on the results of fracture analyses of strengthened systems and on the following assumptions:

- $\quad$ The cross-section remains plane in the deformed configuration; 
- The elasto-plastic constitutive law is considered for concrete (in compression) and reinforcing steel;

- $\quad$ Any strains in the steel reinforcement and concrete are directly proportional to their distance from the neutral axis;

- There is no relative slip between the external reinforcement and the concrete core;

- There is perfect adhesion between the reinforcement and the concrete core, due to negligible shear deformation within the adhesive layer;

- The linear elastic stress-strain constitutive law applies to FRP reinforcement up to failure.

More specifically, these procedures fix the design strain for debonding Modes 1 and 2 in ultimate limit states, as follows:

$$
\varepsilon_{\mathrm{fd}}=\min \left\{\eta_{\mathrm{a}} \cdot \frac{\varepsilon_{\mathrm{fk}}}{\gamma_{\mathrm{f}}}, \varepsilon_{\mathrm{fd}, \mathrm{di}}\right\},
$$

where $\varepsilon_{\mathrm{fk}}$ is the FRP characteristic strain at failure, $\eta_{\mathrm{a}}$ is the FRP environmental reduction factor, $\gamma_{\mathrm{f}}$ is the FRP partial safety factor, and $\varepsilon_{\mathrm{fd}, \mathrm{di}}$ is the maximum strain due to debonding (for the debonding mode $i$-th).

The maximum strain due to the two debonding modes may be given directly or indirectly by the corresponding maximum stress, $f_{\mathrm{fd}, \mathrm{di}}$ (for the debonding mode $i$-th).

In the first case, the ACI 440.2R-17 formulation [12], based on a modified form of the debonding strain equation for Mode 2, proposed by Teng et al. (2003, 2004), may be considered:

$$
\varepsilon_{\mathrm{fd}, \mathrm{d} 2}=0.41 \cdot \sqrt{\frac{f_{\mathrm{fk}}}{n \cdot E_{\mathrm{f}} \cdot t_{\mathrm{f}}}},
$$

In the second case, the Mode 1 failure stress can be evaluated using the following relationship [15]:

$$
f_{\mathrm{fd}, \mathrm{d} 1}=\frac{1}{\gamma_{\mathrm{f}, \mathrm{d}} \cdot \sqrt{\gamma_{\mathrm{c}}}} \cdot \sqrt{\frac{2 \cdot E_{\mathrm{f}} \cdot \Gamma_{\mathrm{Fk}}}{t_{\mathrm{f}}}},
$$

where:

- $\quad E_{\mathrm{f}}$ and $t_{\mathrm{f}}$ are the Young modulus of elasticity and the thickness of the FRP, respectively;

- $\quad \gamma_{\mathrm{f}, \mathrm{d}}$ is the FRP partial factor and $\gamma_{\mathrm{c}}$ is the partial factor for concrete;

- $\quad \Gamma_{\mathrm{Fk}}$ is the specific fracture energy of the FRP-concrete interface, and may be expressed as follows:

$$
\Gamma_{\mathrm{Fk}}=0.03 \cdot k_{\mathrm{b}} \cdot \sqrt{f_{\mathrm{ck}} \cdot f_{\mathrm{ctm}}}
$$

where $f_{\mathrm{ck}}$ and $f_{\mathrm{ctm}}$ are the characteristic strength and the average tensile strength of the concrete, respectively, and $k_{\mathrm{b}}$ is a geometric coefficient dependent on both the width of the strengthened beam and the width of the FRP system.

The Mode 1 failure stress reported above is associated with a bonded length, $l_{\mathrm{b}}$, equal or greater than the optimal length given by [15]:

$$
l_{\mathrm{e}}=\sqrt{\frac{E_{\mathrm{f}} \cdot t_{\mathrm{f}}}{2 \cdot f_{\mathrm{ctm}}}},
$$

If $l_{\mathrm{b}}<l_{\mathrm{e}}$, the ultimate design strength may be reduced as follows:

$$
f_{\mathrm{fd}, \mathrm{d} 1, \mathrm{rid}}=f_{\mathrm{fd}, \mathrm{d} 1} \cdot \frac{l_{\mathrm{b}}}{l_{\mathrm{e}}} \cdot\left(2-\frac{l_{\mathrm{b}}}{l_{\mathrm{e}}}\right),
$$


Mode 2 failure stress may be evaluated using the following relationship [15]:

$$
f_{\mathrm{fd}, \mathrm{d} 2}=k_{\mathrm{cr}} \cdot f_{\mathrm{fdd}}=\frac{k_{\mathrm{cr}}}{\gamma_{\mathrm{f}, \mathrm{d}} \cdot \sqrt{\gamma_{\mathrm{c}}}} \cdot \sqrt{\frac{2 \cdot E_{\mathrm{f}} \cdot \Gamma_{\mathrm{Fk}}}{t_{\mathrm{f}}}},
$$

where $k_{\mathrm{cr}}$ can be taken as equal to 3.0 if specific data are not available.

The corresponding values of the design strain in the FRP system (for the debonding mode $i$-th) can be calculated according to the following expression [15]:

$$
\varepsilon_{\mathrm{fd}, \mathrm{di}}=\frac{f_{\mathrm{fd}, \mathrm{di}}}{E_{\mathrm{f}}} .
$$

\section{Experimental Characterization of the Cohesive Law}

The simplified approaches reported in the previous section may give, in several cases, very conservative ultimate values for the maximum FRP stress allowable to avoid debonding failure.

For this reason, experimental evaluation of the debonding mechanisms is suggested for high-performance reinforcing systems. More specifically, the identification of a cohesive law requires the evaluation of shear slip between the FRP and the structural elements along the loading direction. The former is conventionally measured by means of either linear variable displacement transducers (LVDTs) or laser meter devices installed on the composite plate, located at the beginning of the bonded area. The latter is commonly measured using strain gauges positioned along the longitudinal plane.

While no international standards are currently available, several experimental setups have been proposed in literature [16-26], based on a concrete block reinforced with an FRP laminate subject to a traction force, $F$ (Figure 5).

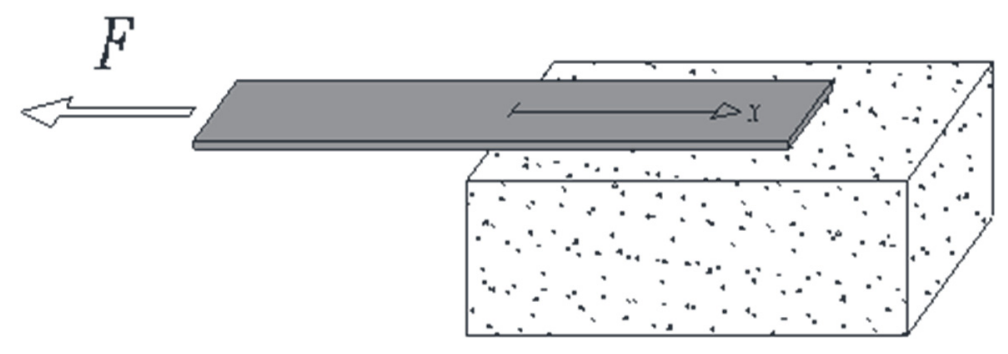

Figure 5. Bond test setup.

Starting from strains in the FRP recorded at fixed points along the $\mathrm{x}$ axis, $\varepsilon_{\mathrm{i}}$, the mean tangential stresses between two subsequent points $\left(x_{\mathrm{i}}\right.$ and $\left.x_{\mathrm{i}+1}\right)$ are given by the following expression:

$$
\tau_{\mathrm{i}, \mathrm{i}+1}=-\frac{E_{\mathrm{f}} A_{\mathrm{f}}\left(\varepsilon_{\mathrm{i}+1}-\varepsilon_{\mathrm{i}}\right)}{b_{\mathrm{f}}\left(x_{\mathrm{i}+1}-x_{\mathrm{i}}\right)}
$$

where $b_{\mathrm{f}}$ and $A_{\mathrm{f}}$ are the FRP width and cross-sectional area, respectively.

The relative displacement between the FRP and the top concrete face (slip), s, provides us with the interface law, which can be modelled using a bilinear or exponential law (Figure 6).

The bilinear law is typically used in the analytical modelling of junctions, while the exponential law is used in their numerical modelling based on FEM codes, due to the continuity of the first derivative. 


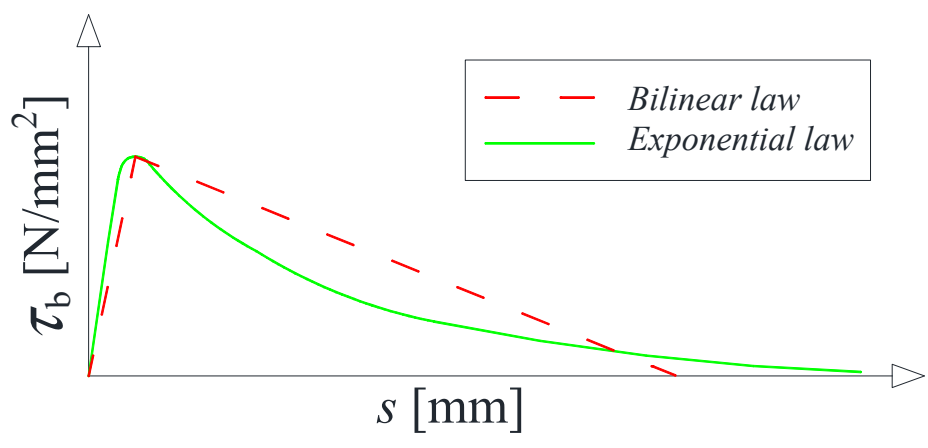

Figure 6. Interface laws.

Starting from the interface law, the fracture energy of the FRP-concrete interface is obtained as follows:

$$
\Gamma_{\mathrm{F}}=\int_{0}^{\infty} \tau_{\mathrm{b}}(s) d s .
$$

The corresponding specific fracture energy can be obtained by identifying the value below which no more than $5 \%$ of test results can be expected to fall.

Some recent studies have proposed the use of Digital Image Correlation (DIC), a non-contact optical technique, to obtain the relative displacement, with measurements made over an extended area of the specimens being tested, rather than measuring only from the beginning of the bonded area [19-26].

This promising method also allows the estimation, with good accuracy, of the strain field acting on the FRP and the external surfaces of concrete core. However, it also exhibits some disadvantages: (i) it requires extensive computing resources, and (ii) it is inaccurate close to the region characterized by displacement discontinuity (e.g., the FRP-substrate slip area). The latter limitation may be overcome by setting suitable parameters for the geometry and position of regions of interest (ROIs) in the DIC analysis (Figure 7).
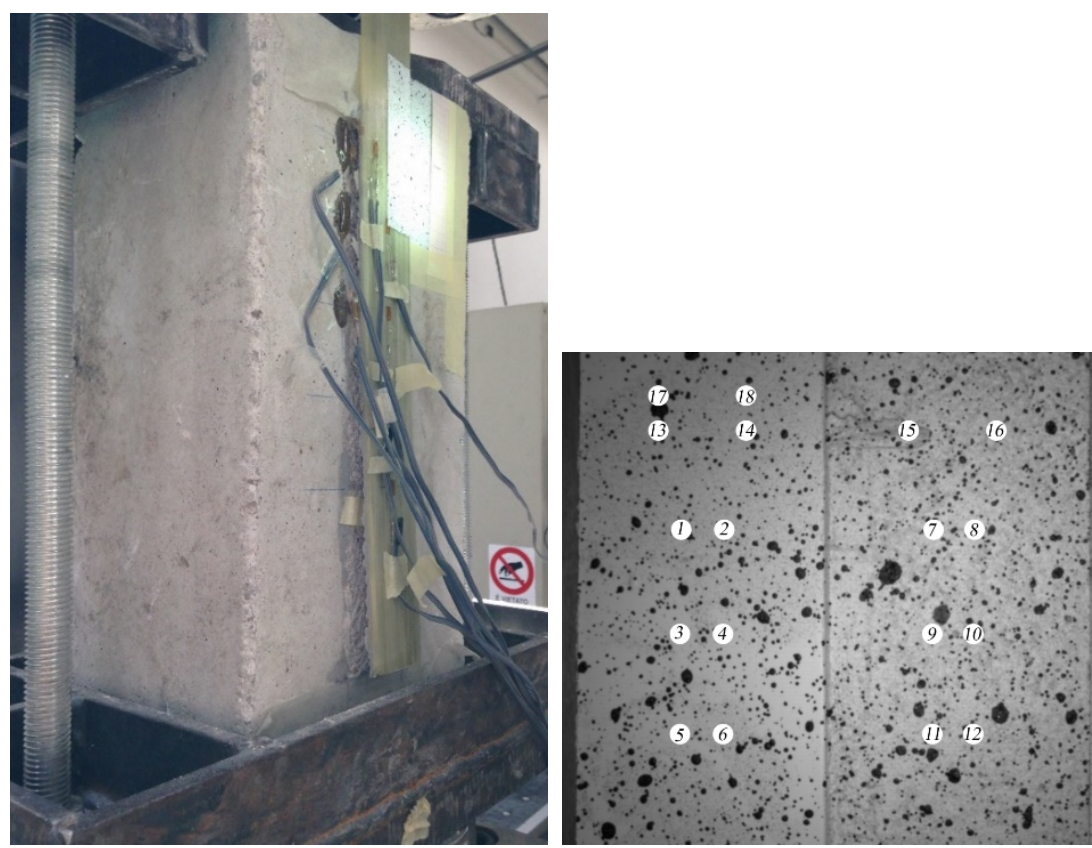

Figure 7. Experimental bond test (left), Region of Interest placed on the composite (right) [25].

A recent methodology [25] allows a direct evaluation of fracture energy without fixing the interface law, by investigating the relationship between the cohesive traction and the J-integral. 
More specifically, this approach assumes that:

- The concrete block is rigid, due to its negligible compliance compared to that of GFRP laminate; this is also confirmed by recordings from the concrete strain gauges;

- $\quad$ The unbounded portion of the GFRP laminate is subject to a pure axial load;

- The bonded interface carries a pure shear load;

- The interface shear is constant over the width of the GFRP laminate;

- The adherends behavior is linear elastic.

Under these hypotheses, the energy release rate, G, may be expressed as:

$$
G(s)=\frac{P(s)^{2}}{2 b_{\mathrm{f}}} \frac{d C(a)}{d a},
$$

where the $P$ is the applied load, $a$ is the current crack length, and $C$ is the compliance of the system given by the following expression:

$$
C(a)=\frac{w(a)}{P}=\frac{l(a)}{E_{\mathrm{f}} A_{\mathrm{f}}}=\frac{l_{0}+a}{E_{\mathrm{f}} A_{\mathrm{f}}},
$$

where $w, l$, and $l_{0}$ are the longitudinal extension, the current length and the initial length of the unbounded portion of the composite, respectively.

The energy release rate, $G$, corresponds to the $J$-integral, $J$, within the field of linear elasticity:

$$
J(s)=G(s)=\frac{P(s)^{2}}{2 b_{\mathrm{f}} A_{\mathrm{f}} E_{\mathrm{f}}} .
$$

Due to the energy release rate failure criterion, it is well known that a crack will grow when the available energy release rate, $G(s)$, is greater than or equal to the critical value, Gc. The parameter $G c$ represents the fracture energy, and is evaluated as:

$$
\mathrm{F}=\frac{P_{\max }^{2}}{2 b_{\mathrm{f}} A_{\mathrm{f}} E_{\mathrm{f}}} .
$$

where $P_{\max }$ is the maximum force recorded during the test.

The corresponding cohesive shear may be evaluated as:

$$
\tau(s)=\frac{\partial J(s)}{\partial s} .
$$

The debonding failure modes may be overcome if anchoring devices are utilized.

Some anchoring systems mentioned in the literature [29-37] and, to a limited extend, available on the market, are based on steel devices or composite elements. These systems require further investigation in order to assess and validate their reliability and durability over time.

Bonded joints may be also utilized in severe conditions of temperature and humidity, which may degrade their bonding strength. Numerous researchers have investigated the durability of bonded joints in aging environments [38-42]. These investigations demonstrated a non-negligible reduction in the peak load of FRP reinforcements and the ultimate displacement of conditioned specimens, even though the trends described by the interfacial law typically do not change. By comparison, FRCM-based strengthening systems are less affected by environmental conditions.

This very different response is mainly due to the different behaviors of the two adhesives: the epoxy adhesive used in FRP laminate may become plastic as it is immersed in water, whereas the mechanical properties of FRCM's cementitious matrix tend to improve when it is immersed in water, due to the positive effects of the additional hydration.

Finally, it can be observed that the debonding failure modes occurring in brittle substrates (concrete or masonry) are different from those seen in ductile substrates (e.g., 
FRP-FRP, FRP-steel elements, honeycomb components). For this reason, the results of studies performed within the context of aeronautics or mechanical engineering $[43,44]$ may not be extended to assess traditional materials used in the field of civil engineering.

\section{Conclusions}

Polymeric matrix composites are currently used for strengthening and repairing existing structures. Despite their numerous advantages, external composite reinforcements exhibit brittle failure mechanisms due to fracture phenomena, and these failures must be taken into account in the design procedure.

This paper gives an overview of debonding behavior and its predictive modelling in externally bonded FRP systems. More specifically, the studies and the guidelines available in the literature propose the simplification both of design approaches and of experimental characterization procedures, in order to evaluate these premature failure modes. The predicted theoretical values may be too conservative, in which case an experimental interface characterization may be justified to optimize the design of the composite reinforcement.

Recent methodologies suggest the use of Digital Image Correlation analysis to identify the CZM that accounts for either the shear interface stress-slip diagram or the analytical relationship between the J-integral and the cohesive traction.

The direct evaluation of the interface law via a shear interface stress-slip diagram may be affected by a more relevant data dispersion with respect to that generally recorded for approaches based on J-integral. For this reason, the newest studies are focused on the J-integral's characterization.

The literature review revealed that some aspects remain to be investigated, such as:

- The long-term behavior of the FRP-substrate interface under various environmental conditions;

- $\quad$ The long-term behavior of FRPs;

- The standard test procedure to experimentally characterize composite systems;

- $\quad$ The standard test procedure to assess the on-site application of FRP systems;

- The efficacy of devices proposed in the literature with respect to debonding phenomena.

Funding: This research received no external funding.

Institutional Review Board Statement: Not applicable.

Informed Consent Statement: Not applicable.

Conflicts of Interest: The author declares no conflict of interest.

\section{References}

1. Ascione, L.; Berardi, V.P.; Feo, L.; Mancusi, G. A numerical evaluation of the inter-laminar stress state in externally FRP plated RC beams. Compos. Part B Eng. 2005, 36, 83-90. [CrossRef]

2. Ghorbani, M.; Mostofinejad, D.; Hosseini, A. Bond behavior of CFRP sheets attached to concrete through EBR and EBROG joints subject to mixed-mode I/II loading. J. Compos. Constr. 2017, 21, 04017034. [CrossRef]

3. Mansouri, I.; Hu, J.W.; Kisi, O. Novel predictive model of the debonding strength for masonry members retrofitted with FRP. Appl. Sci. 2016, 6, 337. [CrossRef]

4. Sciarretta, F. Seismic retrofitting of traditional masonry with pultruded FRP profiles. Appl. Sci. 2020, 10, 2489. [CrossRef]

5. Carozzi, F.G.; Colombi, P.; Fava, G.; Poggi, C. A cohesive interface crack model for the matrix-textile debonding in FRCM composites. Compos. Struct. 2016, 143, 230-241.

6. Bilotta, A.; Ceroni, F.; Lignola, G.P.; Prota, A. Use of DIC technique for investigating the behaviour of FRCM materials for strengthening masonry elements. Compos. Part B Eng. 2017, 129, 251-270. [CrossRef]

7. Calabrese, A.S.; D'Antino, T.; Colombi, P.; Carloni, C.; Poggi, C. Fatigue behavior of PBO FRCM composite applied to concrete substrate. Materials 2020, 13, 2368. [CrossRef] [PubMed]

8. Al-Lami, K.; D'Antino, T.; Colombi, P. Durability of fabric-reinforced cementitious matrix (FRCM) composites: A review. Appl. Sci. 2020, 10, 1714. [CrossRef]

9. Shukri, A.A.; Ud Darain, K.M.; Jumaat, M.Z. The tension-stiffening contribution of NSM CFRP to the behavior of strengthened RC beams. Materials 2015, 8, 4131-4146. [CrossRef] [PubMed] 
10. Bakalarz, M.M.; Kossakowski, P.G.; Tworzewski, P. Strengthening of bent LVL beams with near-surface mounted (NSM) FRP reinforcement. Materials 2020, 13, 2350. [CrossRef] [PubMed]

11. Yeboah, D.; Gkantou, M. Investigation of flexural behaviour of structural timber beams strengthened with NSM basalt and glass FRP bars. Structures 2021, 33, 390-405. [CrossRef]

12. ACI Committee. ACI 440.2R-17: Guide for the Design and Construction of Externally Bonded FRP Systems for Strengthening Concrete Structures; American Concrete Institute (ACI): Farmington Hills, MI, USA, 2017.

13. Fib TG 9. 3. Technical Report on the Design and Use of Externally Bonded Fibre Reinforced Polymer Reinforcement (FRP EBR) for Reinforced Concrete Structures; Technical report; Sprint-Digital-Druck: Stuttgart, Germany, 2001.

14. Fib. Externally Applied FRP Reinforcement for Concrete Structures; Bullettin 90; DCC Document Competence Center Siegmar Kästl e.K.: Ostfildern, Germany, 2019.

15. National Research Council of Italy. Guide for the Design and Construction of Externally Bonded FRP Systems for Strengthening Existing Structures-CNR-DT 200R1-2013; Advisory Committee on Technical Regulations for Constructions: Rome, Italy, 2013.

16. Mazzotti, C.; Savoia, M.; Ferracuti, B. A new single-shear set-up for stable debonding of FRP-concrete joints. Constr. Build. Mater. 2009, 23, 1529-1537. [CrossRef]

17. Bencardino, F.; Condello, A.; Ashour, A.F. Single-lap shear bond tests on Steel Reinforced Geopolymeric Matrix-concrete joints. Compos. Part B Eng. 2017, 110, 62-71. [CrossRef]

18. Gustavo, J.; Galati, N.; Nanni, A. Fiber-reinforced polymer strengthening of unreinforced masonry walls subject to out-of-plane loads. ACI Struct. J. 2003, 100, 321-329.

19. Ali-Ahmad, M.; Subramaniam, K.; Ghosn, M. Experimental investigation and fracture analysis of debonding between concrete and FRP sheets. J. Eng. Mech. 2006, 132, 914-923. [CrossRef]

20. Carloni, C.; Subramaniam, K.V. Direct determination of cohesive stress transfer during debonding of FRP from concrete. Compos. Struct. 2010, 93, 184-192. [CrossRef]

21. Carozzi, F.G.; Colombi, P.; Poggi, C. Calibration of end-debonding strength model for FRP-reinforced masonry. Compos. Struct. 2015, 120, 366-377. [CrossRef]

22. Tekieli, M.; De Santis, S.; de Felice, G.; Kwiecien', A.; Roscini, F. Application of Digital Image Correlation to composite reinforcements testing. Compos. Struct. 2017, 160, 670-688. [CrossRef]

23. Pohoryles, D.A.; Melo, J.; Rossetto, T.; Fabian, M.; McCague, C.; Stavrianaki, K.; Lishman, B.; Sargeant, B. Use of DIC and AE for monitoring effective strain and debonding in FRP and FRCM-retrofitted RC beams. J. Compos. Constr. 2017, 21, 04016057. [CrossRef]

24. Perrella, M.; Berardi, V.P.; Cricrì, G. A novel methodology for shear cohesive law identification of bonded reinforcements. Compos. Part B Eng. 2018, 144, 126-133. [CrossRef]

25. Berardi, V.P.; Perrella, M.; Cricrì, G. Cohesive fracture in composite systems: Experimental setup and first results. Frattura ed Integrita Strutturale 2019, 13, 222-229. [CrossRef]

26. Richefeu, V.; Chrysochoos, A.; Huon, V.; Monerie, Y.; Peyroux, R.; Wattrisse, B. Toward local identification of cohesive zone models using digital image correlation. Eur. J. Mech. A Solids 2012, 34, 38-51. [CrossRef]

27. Campilho, R.D.S.G. Strength Prediction of Adhesively-Bonded Joints; Taylor \& Francis Group CRC Press: Boca Raton, FL, USA, 2017; ISBN 978-1-4987-2246-9.

28. Cricrì, G. Cohesive law identification of adhesive layers subject to shear load-An exact inverse solution. Int. J. Solids Struct. 2019, 158, 150-164. [CrossRef]

29. Attari, N.; Amziane, S.; Chemrouk, M. Efficiency of beam-column joint strengthened by FRP laminates. Adv. Compos. Mater. 2010, 19, 171-183. [CrossRef]

30. El-Amoury, T.; Ghobarah, A. Seismic rehabilitation of beam-column joint using GFRP sheets. Eng. Struct. 2002, 24, 1397-1407. [CrossRef]

31. Ceroni, F.; Pecce, M.; Matthys, S.; Taerwe, L. Debonding strength and anchorage devices for reinforced concrete elements strengthened with FRP sheets. Compos. J. Part B 2008, 39, 429-441. [CrossRef]

32. Diab, H.; Wu, Z.; Iwashita, K. Short and long-term bond performance of prestressed FRP sheet anchorages. Eng. Struct. 2009, 31, 1241-1249. [CrossRef]

33. Bousselham, A. State of research on seismic retrofit of RC beam-column joints with externally bonded FRP. J. Compos. Constr. 2010, 14, 49-61. [CrossRef]

34. Ascione, L.; Berardi, V.P. Anchorage device for FRP laminates in the strengthening of concrete structures close to beam-column joints. Compos. Part B Eng. 2011, 42, 1840-1850. [CrossRef]

35. Akhlaghi, A.; Mostofinejad, D. Effectiveness of a novel anchorage system for flexural strengthening of RC beam-column joints using CFRP sheets. In Proceedings of the 9th International Conference on Fibre-Reinforced Polymer (FRP) Composites in Civil Engineering (CICE 2018), Paris, France, 17-19 July 2018; pp. 163-169.

36. Smith, S.T.; Shrestha, R. A review of FRPstrengthened RC beamcolumn connections. In Proceedings of the 3th International Conference on Fibre-Reinforced Polymer (FRP) Composites in Civil Engineering (CICE 2006), Miami, FL, USA, 13-15 December 2006; 2020; pp. 661-664.

37. Ravichandran, K.; Prsadkrishnan, A.K. Behaviour of beam-column joints under cyclic loading. In Lecture Notes in Civil Engineering; Springer: Berlin, Germany, 2021; Volume 111, pp. 115-125. 
38. Ceroni, F.; Bonati, A.; Galimberti, V.; Occhiuzzi, A. Effects of environmental conditioning on the bond behavior of FRP and FRCM systems applied to concrete elements. J. Eng. Mech. 2018, 144, 04017144. [CrossRef]

39. De Domenico, D.; Urso, S.; Borsellino, C.; Spinella, N.; Recupero, A. Bond behavior and ultimate capacity of notched concrete beams with externally-bonded FRP and PBO-FRCM systems under different environmental conditions. Constr. Build. Mater. 2020, 265, 121208. [CrossRef]

40. Li, J.; Li, Y.; Xiang, Y.; Pan, Q.; Chen, C.; Liu, J.; Hu, X. Effect of hygrothermal-mechanical exposure on the residual strength of adhesively bonded joints. Int. J. Adhes. Adhes. 2020, 100, 102616. [CrossRef]

41. Brewis, D.M.; Comyn, J.; Shalash, R.J.A. The Effect of Moisture and Temperature on the Properties of an Epoxide-Polyamide Adhesive in Relation to Its Performance in Single Lap Joints; Composites, Butterworth \& Co: Oxford, UK, 1982.

42. Hu, P.; Han, X.; da Silva, L.F.M.; Li, W.D. Strength prediction of adhesively bonded joints under cyclic thermal loading using a cohesive zone model. Int. J. Adhes. Adhes. 2013, 41, 6-15. [CrossRef]

43. Saseendran, V.; Berggreen, C.; Krueger, R. Mode mixity analysis of face/core debonds in a single cantilever beam sandwich specimen. J. Sandw. Struct. Mater. 2020, 22, 1879-1909. [CrossRef]

44. Saseendran, V.; Berggreen, C.; Carlsson, L.A. Fracture mechanics analysis of reinforced DCB sandwich debond specimen loaded by moments. AIAA J. 2018, 56, 413-422. [CrossRef] 